\title{
Optimal power flow model for building integrated photovoltaic systems operating in the andean range
}

\author{
Aristizabal A.J. ${ }^{1}$, Ospina D. ${ }^{2}$, Castaneda M. ${ }^{3}$, Zapata S. ${ }^{4}$, Banguero E ${ }^{5}$ \\ ${ }^{1,3,4}$ Engineering Department, Universidad de Bogotá Jorge Tadeo Lozano, Colombia \\ ${ }^{2}$ Mewbourne College of Earth and Energy, The University of Oklahoma, United Sates of America, North America \\ ${ }^{5}$ Enginnering Production Program, Universitat Politécnica de Valencia, Spain
}

\begin{tabular}{l}
\hline Article Info \\
\hline Article history: \\
Received Jan 25, 2019 \\
Revised Apr 27, 2019 \\
Accepted May 18, 2019 \\
\hline Keywords: \\
BIPVS performance \\
Distributed generation \\
Photovoltaic systems \\
Power flow model \\
Solar energy
\end{tabular}

\begin{abstract}
This paper presents a novel model to evaluate the power output of a building integrated photovoltaic system (BIPVS) operating in the Andean Range. The Optimal Power Flow (OPF) model optimizes the power output of the BIPVS within an electrical system without violating operational limits. The model is validated with the experimental performance of a $6 \mathrm{~kW}$ BIPVS installed in Bogota, Colombia. The meteorological data affect the power flow. The model is evaluated under sunny and rainy days to characterize the photovoltaic array performance. The results showed that the AC PV-energy generation was 5,904 kWh/year for 2017 and that there is a correlation factor of $99.87 \%$ between the experimental power flow and the proposed model.
\end{abstract}

Copyright (C) 2019 Institute of Advanced Engineering and Science. All rights reserved.

\section{Corresponding Author:}

Aristizabal A.J.,

Engineering Department,

Universidad de Bogotá Jorge Tadeo Lozano,

Bogotá, Colombia.

Email: andresj.aristizabalc@utadeo.edu.co

\section{INTRODUCTION}

Building Integrated Photovoltaic Systems technology allows the use of the façade or the roof of buildings of any type to produce electricity (or thermal heat in the case of solar collectors) and in this way the building reduces its energy demand. These technologies integrated into buildings allow developing various designs of structures in broad ways [1]. The photovoltaic generator (PV), the main component of PV technology, is responsible for the efficiency and durability of the entire system. This generator is used by many designers to replace parts of the structure of buildings such as ceilings or walls. The meteorological variables directly affect the performance of an interconnected photovoltaic system generating losses and affecting the economic balance of the System [2].

There are worldwide different standards that establish the requirements for the connection of photovoltaic systems interconnected with the electricity grid. These standards aim to ensure the safety of people and equipment. Conventional generation of electricity has been through hydropower and renewable energy generators are being used recently to produce electricity [3].

One of the advantages of the building integrated photovoltaic systems, is that they can reduce the space and the cost of certain equipment if they are used to be installed in structures [4-6]. In the case of thermal energy, changes in temperature and energy transfer to the interior of the building, makes the process not easy, [7- 10], which directly affects the entire structure where the System is installed [11].

Traditionally, power distributions grids deliver power in a single direction, to supply the electricity required by users. Energy companies are responsible for purchasing power in the electricity market and selling it to the end user at defined prices [12]. 
The analysis of the optimal power flow (OPF) represents a valuable technical-economic technique. With this type of analysis it is possible to optimize a specific variable of the Power System in order to guarantee the reliability and the proper operation of the energy processes [13].

There are in literature several papers showing methods to evaluate the operational results of photovoltaic generators and the impact of meteorological data [14-21] and to develop different non-linear electric models used to describe the characteristics of the PV modules under non-standard conditions [22-29]. This paper presents a method to model the optimal power flow of BIPV systems. Section 2 addresses the BIPVS model dynamics. Section 3 presents the designing process of the OPF model. In Section 4, to approve the developed model, monitored data from one photovoltaic generator in Bogota, Colombia is utilized to make comparison with the proposed OPF method. Conclusions with discussions are given in Section 5.

\section{BUILDING INTEGRATED PHOTOVOLTAIC SYSTEM MODELLING}

The BIPV system performance is influenced by solar irradiance and ambient temperature. These variables are dependent of the specific installation site and must be analysed for a period of one year. The electric components of the BIPV system are modelled as follows.

\subsection{Photovoltaic Current}

Each solar cell behaves in the dark in a similar manner to a $\mathrm{p} / \mathrm{n}$ rectifying diode, and generates an electrical photocurrent under the incidence of light. The photovoltaic current is given by:

$$
I p h=\frac{G}{1000}[I s c+\Delta i(T-T r)]
$$

$\mathrm{G}$ is the radiation in the existing site, $\mathrm{T}$ and $\mathrm{Tr}$ are the site's current temperature and the reference temperature, $\Delta \mathrm{i}$ is the current temperature coefficient and Isc is the short-circuit current of the cell at standard temperature. The solar cells integrating the solar module are described by:

$$
I=I_{p h}-I_{S} *\left(e^{\left(\frac{V+R_{S} * I}{n * V t}\right)}-1\right)-\frac{V+R_{S} * I}{R_{s h}}
$$

Where, Is is the saturation current of the diode, $\mathrm{V}$ is the saturation voltage, Rs is the series resistor of the module and Rsh is shunt resistor module.

\subsection{Inverter Model}

The PV inverter is modelled as a voltage element that supplies the current described by this equation:

$$
I_{R M S}=\frac{V_{m p p^{* I}} I_{m p} * n f}{\operatorname{Vred}_{R M S}}
$$

Where Vmpp is the maximum power point at the inverter input and $\mathrm{nf}$ is the efficiency.

\subsection{Electrical Grid Model}

This proposed model is an RLC circuit with a power factor equal to 0.85 . The following expression gives the angle for that variable:

$$
\theta=\arccos (0.85)=31.7^{\circ} \approx 30^{\circ}
$$

Taking expression (5) into account, values are calculated with $\mathrm{R}=3 \Omega, \mathrm{X}=\sqrt{\mathbf{3}}$. Inductive (XL) and capacitive (XC) reactance are evaluated using (6) and (7).

$$
\begin{aligned}
& \operatorname{Tan} \theta=\frac{\left(X_{L}-X_{C}\right)}{R}=\frac{\sqrt{3}}{3} \\
& X_{C}=\frac{1}{2 * \pi * f * C} \\
& X_{L}=2 \pi f L
\end{aligned}
$$

With $\mathrm{L}=2 \mathrm{H}$ and equation (8), we can calculate the capacitance $(\mathrm{C})$ : 
$C=\frac{1}{\omega^{2} L-\omega \sqrt{3}}=3.526 * 10^{-6} \mathrm{~F}$

\section{OPTIMAL POWER FLOW MODEL}

The OPF problem is as [13]:

$$
\min f(z) ; s . t .:\left\{\begin{array}{l}
I_{R e}(z)=0, \quad I_{I m}(z)=0 \\
g(z)=0, \quad h(z)=0 \\
\underline{z} \leq z \leq \bar{z}
\end{array}\right.
$$

$f(z)$ represents the objective function; I is the total current applied to all points; $g(z)$ and $h(z)$ are the inequality constraints, respectively; and $\mathrm{z}$ denotes the state and control variables.

The Lagrange function is the following:

$$
\begin{aligned}
& L(z, \lambda, \pi)=f(z)-\sum_{i=1}^{N} \lambda_{I m, i} I_{R e, i}(z)-\sum_{i=1}^{N} \lambda_{R e, i} I_{I m, i}(z)-\sum_{i=1}^{n i} \lambda_{i} g_{i}(z)-\sum_{j=1}^{n d} \pi_{j .1}\left(z_{j}-z_{j . m i n} s l_{j .1}\right)-\mu b \sum_{j=1}^{n d} \log \left(s l_{j .1)}-\right. \\
& \sum_{j=1}^{n d} \pi_{j .2}\left(z_{j}-z_{j . \max }-s l_{j .2}\right)-\mu b \sum_{j=1}^{n d} \log \left(s l_{j .2}\right)
\end{aligned}
$$

In this equation, ni is the total of restrictions, nd is the total of inequality restrictions; $\lambda_{\boldsymbol{R} e}, \boldsymbol{\lambda}_{\mathrm{Im}}, \boldsymbol{\pi}_{\mathbf{1}}$ and $\boldsymbol{\pi}_{\mathbf{2}}$ represent the Lagrange factors; sl= group of variation range; and $\boldsymbol{\mu b}>\mathbf{0}$ is the barrier variable [13]. Then, our method is described by:

$$
\nabla^{2} L(z, \lambda) \cdot \Delta(z, \lambda)=-\nabla L(z, \lambda)
$$

$\boldsymbol{\nabla}^{2} \boldsymbol{L}(\boldsymbol{z}, \lambda)$ represent the Hessian matrix and $\boldsymbol{\nabla} \boldsymbol{L}(\boldsymbol{z}, \boldsymbol{\lambda})$ is the first-order derivatives.

Finally, our system is described by:

$$
\min _{E_{1}}\left\{\begin{array}{c}
\Delta V\left(\begin{array}{c}
E_{1}, E_{1}(t+d t), E_{2}, E_{2}(t+d t), \\
\ldots, E_{M}, E_{M}(t+d t) \\
E_{M}(t+d t)
\end{array}\right) \\
+V\left(t+d t, E_{1}(t+d t), E_{2}(t+d t),\right. \\
\left.\ldots, E_{M}(t+d t)\right)
\end{array}\right\}
$$

where V(.) is defined as [30].

\section{VALIDATION RESULTS AND DISCUSSION}

\subsection{System Description}

The energy output of the proposed model is verified with measured data from a $6 \mathrm{~kW}$ BIPV system. The BIPV system is installed in Bogotá, at 4\%35' latitude and $2.580 \mathrm{~m}$ altitude, on the roof of the "Researching Center of the Engineering Programs - CIPI" building at Universidad de Bogotá Jorge Tadeo Lozano. The BIPV system is composed of 24 photovoltaic modules connected to the electrical grid through a 5000W SMA inverter. A monitoring system was implemented using virtual instrumentation to measure irradiance, ambient temperature and DC-AC variables of the photovoltaic system [9].

Table 1 shows the data sheet of the PV modules used as photovoltaic generator. Table 2 shows the characteristics of the SB 5000TL-US inverter. Figure 1 is an exterior view of a part of the PV array seen from the southeast side of building's roof.

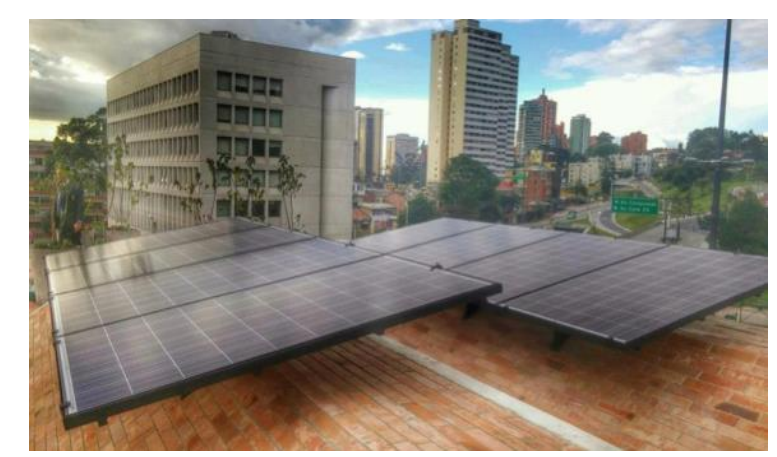

Figure 1. External view of the BIPV system in the laboratory building 


\subsection{BIPVS Performance}

The BIPVS energy production was evaluated for every month of 2017. Figure 2 shows the variation of the photovoltaic array's energy and the AC inverter's energy.

Due to the location of Bogotá on the Andean range, the presence of clouds is permanent and energy production varies along the whole year. The DC output energy averages $676.2 \mathrm{kWh}$-day for 2017, with a minimum of $548.3 \mathrm{kWh}$-day in September and a maximum of 780,6 kWh-day in January. The DC energy includes the conversion losses from solar irradiance to electricity by the solar panels.

The AC output energy averages $585.4 \mathrm{kWh}$-day for 2017, with a minimum of $482.2 \mathrm{kWh}$-day in September and a maximum of $679,8 \mathrm{kWh}$-day in February. The AC energy includes the conversion losses from DC power to AC power by the solar inverter.

Figure 3 shows the efficiencies variation: inverter, PV array and BIPVS efficiencies. The inverter performance was according to the manufacturer's data sheet: its efficiency varied between $90 \%$ and $96 \%$.

The PV array efficiency averaged $13.2 \%$ for the year of monitoring, with a minimum of $11.3 \%$ in September and a maximum of $14.2 \%$ in November. BIPVS efficiency is the lowest of those presented, because its calculus includes the PV array and the DC/AC inverter losses. Its average was 10.4\%/year with a variation between $9.8 \%$ and $11.2 \%$.

Table 1. Electrical Specifications of the PV Module

\begin{tabular}{ll}
\hline Electrical data in STC conditions & Value \\
\hline Rated Power-Pmax (Wp) & 250 \\
Rated power tolerance (\%) & $0 /+3$ \\
Voltage at the point Pmax-Vmpp (V) & 29.8 \\
Current at the Pmax-Impp point (A) & 8.38 \\
Open Circuit Voltage-Voc (V) & 38.1 \\
Short circuit current-Isc (A) & 8.91 \\
Module Efficiency $\eta m \%$ & 15.3 \\
Number of cells in series & 60 \\
Nominal Operating Temperature $\left({ }^{\circ} \mathrm{C}\right)$ & 44 \\
Kv. Temperature coefficient Voc $(\% / \mathrm{K})$ & -0.32 \\
Ki. Temperature coefficient Isc $(\% / \mathrm{K})$ & 0.053 \\
\hline
\end{tabular}

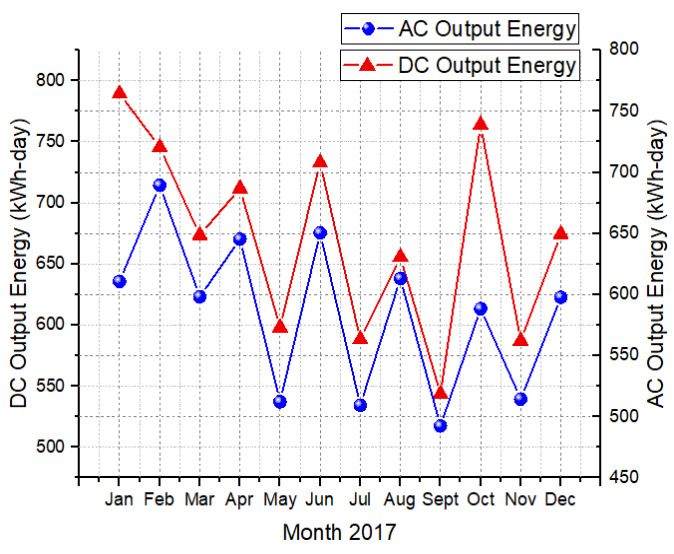

Figure 2. Yearly profile of the DC and AC Energy in Bogotá for 2017
Table 2. Technical Data of the Selected Inverter

\begin{tabular}{lc}
\hline Technical data & Value \\
\hline DC Maximum input power (W) & 5300 \\
DC Rated Voltage (Vdc) & 310 \\
Minimum DC Voltage (Vdc) & 250 \\
Inverter starter voltage (Vdc) & 300 \\
Operating voltage (Vac) & 208 \\
AC Rated power (W) & 5000 \\
Frequency of the grid (Hz) & 60 \\
Maximum output current (Aac) & 24 \\
Efficiency (\%) & 96.7
\end{tabular}

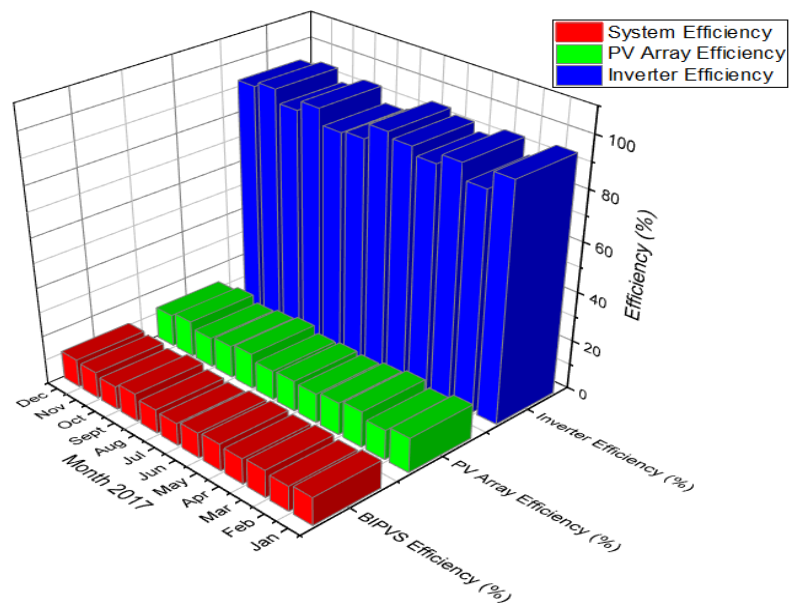

Figure 3. Efficiency data of the different components of the photovoltaic system for 2017: inverter, solar panels, complete system (includes from the inlet of the solar panels to the inverter output)

\subsection{OPF Model Results}

The daily monitoring is activated between 6 am and $6 \mathrm{pm}$, acquiring 1 sample per minute of meteorological and electrical variables. The DC and AC output power of the model is obtained by dividing energy in $\mathrm{kWh}$ by $12 \mathrm{~h}$ (daily monitoring period).

The results are verified considering two kinds of weather conditions: sunny and cloudy. Figures 4 and 5 show the comparison between measured (blue line) and simulated, with the OPF model, (red line) power output for a sunny day (18th January 2017) and a cloudy day (9th October 2017).

\footnotetext{
Optimal power flow model for building integrated photovoltaic systems operating in... (Aristizabal A.J.)
} 


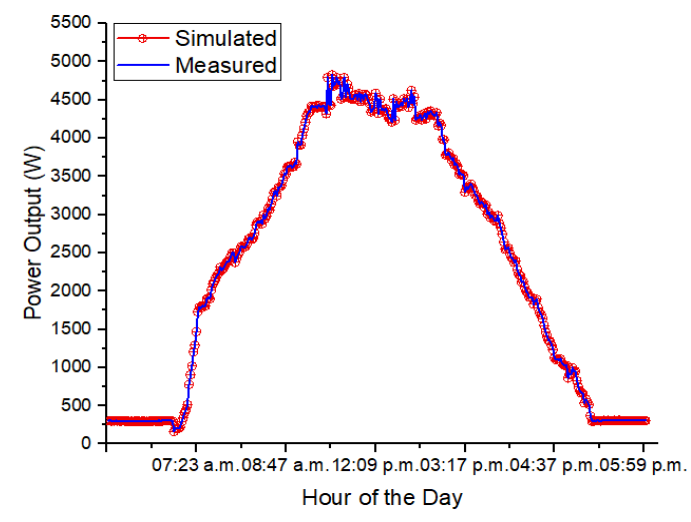

Figure 4. Comparison between the measured and simulated power output for a sunny day

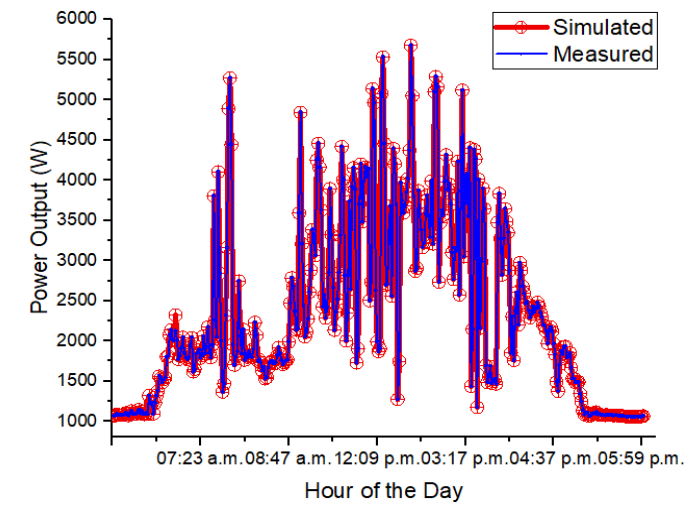

Figure 5. Comparison between the measured and simulated power output for a cloudy day

The OPF model results followed the measured power output quite well. In Figure 4 the maximum power output was $4834 \mathrm{~W}$ produced at noon and the OPF model registered $4833.8 \mathrm{~W}$ for the same point. In Figure 5 is possible to see the effect of the Andean range: clouds passing over the PV array along the day. Because of this, the BIPV system efficiency is affected by the reduced solar irradiance over the solar panels.

Figures 6 and 7 show the correlation between measured (blue line) and simulated, OPF model, (red line) power output for the same sunny and cloudy days. Both figures plot the power output versus the measured solar irradiance.

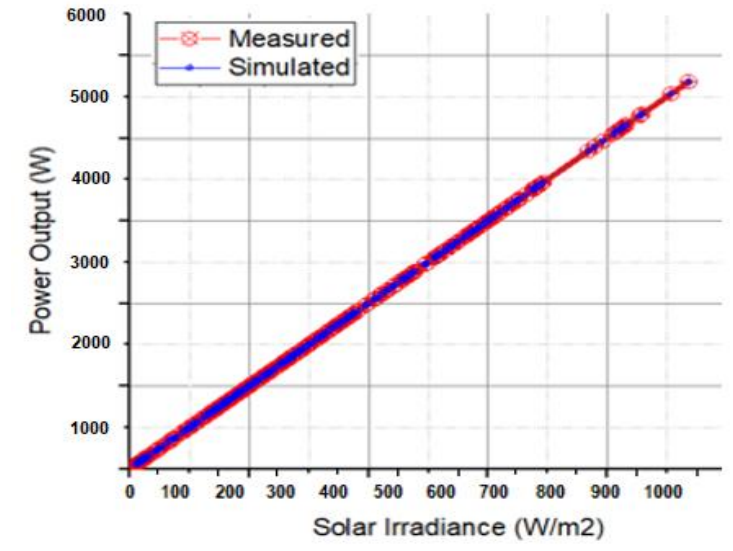

Figure 6. Correlation between the measured and the simulated output power for a sunny day

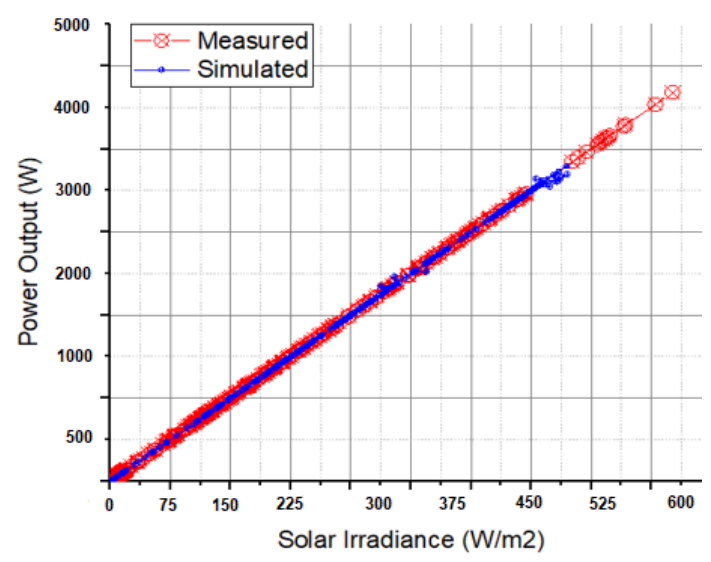

Figure 7. Correlation between the measured and the simulated output power for a cloudy day

In Figure 6 the maximum power output is reached at the standard solar irradiance of $1000 \mathrm{~W} / \mathrm{m} 2$ presented at noon and it's according to the results presented in Figure 4. This happens because the current photogenerated by the solar panels is directly proportional to the incident solar radiation, allowing to reach the maximum power generation of the System. Thanks to the absence of clouds, there is no dispersion in the data.

In Figure 7, due to the cloudiness condition, the maximum recorded solar radiation was $600 \mathrm{~W} / \mathrm{m} 2$ and the maximum power generated for this case was $4000 \mathrm{~W}$. This condition also causes small dispersion on data observed. Table 3 shows the correlation results of the experimental analysis.

Table 3. Correlation Results for Both Days

\begin{tabular}{cc}
\hline $\mathrm{R}^{2}$ & BIPV System \\
\hline Sunny & $99.87 \%$ \\
Cloudy & $99.62 \%$ \\
\hline
\end{tabular}




\section{CONCLUSIONS}

The performance of the BIPV system fulfills the initial design that was expected to produce an average of $504 \mathrm{kWh}$-day, and the average measured was $585.4 \mathrm{kWh}$-day. The additional energy (85 kWh-day) was possible due to the good solar irradiance conditions during 2017.

Results about the BIPV system efficiency are also presented. These showed an average of $13.2 \%$ for the photovoltaic array while the AC/DC inverter registered an average of $94.2 \%$.

This paper presented an OPF model for BIPV systems operating in the Andean range. The model results are validated under different weather conditions. The correlation coefficient for a sunny day registered a value of $99.87 \%$ and $99.62 \%$ for a cloudy day.

Changes in the national energy regulations as well as support for funding renewable energy generation systems could be incentives for people to install residential photovoltaic systems massively in Colombia.

\section{ACKNOWLEDGEMENTS}

This work was supported by Universidad de Bogotá Jorge Tadeo Lozano under Grant 830-15-17.

\section{REFERENCES}

[1] T. Yang and A. K. Athienitis, "A review of research and developments of building-integrated photovoltaic/thermal (BIPV/T) systems,” Renew. Sustain. Energy Rev., vol. 66, pp. 886-912, 2016.

[2] O. Hachana, G. M. Tina, and K. E. Hemsas, "PV array fault DiagnosticTechnique for BIPV systems," Energy Build., vol. 126, pp. 263-274, 2016.

[3] A. Cabrera-Tobar, E. Bullich-Massagué, M. Aragüés-Peñalba, and O. Gomis-Bellmunt, "Review of advanced grid requirements for the integration of large scale photovoltaic power plants in the transmission system," Renew. Sustain. Energy Rev., vol. 62, pp. 971-987, 2016.

[4] T. Yang and A. K. Athienitis, "A study of design options for a building integrated photovoltaic/thermal (BIPV/T) system with glazed air collector and multiple inlets,” Sol. Energy, vol. 104, pp. 82-92, 2014.

[5] L. Stamenic, E. Smiley, and K. Karim, "Low light conditions modelling for building integrated photovoltaic (BIPV) systems," Sol. Energy, vol. 77, no. 1, pp. 37-45, 2004.

[6] R. Eke and A. Senturk, "Monitoring the performance of single and triple junction amorphous silicon modules in two building integrated photovoltaic (BIPV) installations," Appl. Energy, vol. 109, pp. 154-162, 2013.

[7] X. Zhang, X. Zhao, S. Smith, J. Xu, and X. Yu, "Review of R\&D progress and practical application of the solar photovoltaic/thermal (PV/T) technologies," Renew. Sustain. Energy Rev., vol. 16, no. 1, pp. 599-617, 2012.

[8] B. Agrawal and G. N. Tiwari, "Optimizing the energy and exergy of building integrated photovoltaic thermal (BIPVT) systems under cold climatic conditions,” Appl. Energy, vol. 87, no. 2, pp. 417-426, 2010.

[9] A. J. Aristizábal and C. A. Páez, "Experimental investigation of the performance of $6 \mathrm{~kW}$ BIPV system applied in laboratory building", Energy and Buildings, vol. 152, 2017.

[10] T. T. Chow, G. Pei, K. F. Fong, Z. Lin, A. L. S. Chan, and J. Ji, "Energy and exergy analysis of photovoltaicthermal collector with and without glass cover," Appl. Energy, vol. 86, no. 3, pp. 310-316, 2009.

[11] Z. Wang, J. Zhang, Z. Wang, W. Yang, and X. Zhao, "Experimental investigation of the performance of the novel HP-BIPV/T system for use in residential buildings," Energy Build., vol. 130, pp. 295-308, 2016.

[12] S. Bahramara, M. Parsa Moghaddam, and M. R. Haghifam, "A bi-level optimization model for operation of distribution networks with micro-grids," Int. J. Electr. Power Energy Syst., vol. 82, pp. 169-178, 2016.

[13] H. Abdi, S. D. Beigvand, and M. La Scala, "A review of optimal power flow studies applied to smart grids and microgrids,” Renew. Sustain. Energy Rev., vol. 71, no. May 2015, pp. 742-766, 2017.

[14] Aristizábal A.J., Páez C.A. and Chica A.D.J., "Parameters identification of photovoltaic modules for estimating the power generated under non-standad conditions", International Journal of Modelling and Simulation, vol. 37, no. 4, pp. 252-261, 2017.

[15] M. Salem and Y. Atia, "Control scheme towards enhancing power quality and operational efficiency of singlephase two-stage grid-connected photovoltaic systems," J. Electr. Syst. Inf. Technol., vol. 2, no. 3, pp. 314-327, 2015.

[16] F. Frontini, S. M. Bouziri, G. Corbellini, and V. Medici, "S.M.O Solution: An Innovative Design Approach to Optimize the Output of BIPV Systems Located in Dense Urban Environments," Energy Procedia, vol. 91, pp. 945-953, 2016.

[17] Banguero E., Aristizábal A.J. and Murillo W., “A verification study for grid-connected $20 \mathrm{~kW}$ solar PV system operating in Chocó, Colombia", Energy Procedia, vol. 141, pp. 96-101, 2017.

[18] [V. Delisle and M. Kummert, "Cost-benefit analysis of integrating BIPV-T air systems into energy-efficient homes," Sol. Energy, vol. 136, pp. 385-400, 2016.

[19] H. J. Kuo, S. H. Hsieh, R. C. Guo, and C. C. Chan, "A verification study for energy analysis of BIPV buildings with BIM,” Energy Build., vol. 130, pp. 676-691, 2016.

[20] Banguero E., Correcher A., Perez-Navarro A., Morant F., and Aristizabal A., "A review on battery charging and discharging control strategies: Application to renewable energy systems" Energies, vol. 11, no. 4, art. no. 1021, 2018 . 
[21] Zapata S., Castaneda M., Jimenez M., Julian Aristizabal A., Franco C.J. and Dyner I., "Long-term effects of $100 \%$ renewable generation on the Colombian power market", Sustainable Energy Technologies and Assessments, vol. 30, pp. 183-191, 2018.

[22] Hicham Bahri, Mohamed Aboulfatah, M'hammed Guisser, Elhassane Abdelmounim, Mohammed El Malah, "Integral Backstepping Control for Maximum Power Point Tracking Factor of a Three Phase Grid Connected Photovoltaic System", International Journal of Electrical and Computer Engineering, Vol. 7, no. 4, pp. 1671-1680, August 2017.

[23] Mustapha Elyaqouti, Lahaoussine Bouhouch, Ahmed Ihal, "Modelling and Predicting of the Characteristics of a Photovoltaic Generator on a Horizaontal and Tilted Surface", International Journal of Electrical and Computer Engineering, Vol. 6, no. 6, pp. 2257-2576, December 2016.

[24] Amirullah, Agus Kiswantono, "Power Quality Enhancement of Integration Photovoltaic Generator to Grid under Variable Solar Irradiance Level Using MPPT-Fuzzy", International Journal of Electrical and Computer Engineering, Vol. 6, no. 6, pp. 2629-2642, December 2016.

[25] Murari Lal Azad, Pradip Kumar Sadhu, Soumya Das, Biplab Satpati, Anagh Gupta, P. Arvind, Riya Biswas, "An Improved Approach to Design a Photovoltaic Panel", Indonesian Journal of Electrical Engineering and Computer Science, Vol. 5, no. 3, pp. 515-520, March 2017.

[26] Syafii, Roni Putra, Hasdi Putra, "Online Monitoring of Grid Connected Residential Photovoltaic System using Zigbee and Web Server", Indonesian Journal of Electrical Engineering and Computer Science, Vol. 7, no. 3, pp. 668-675, September 2017.

[27] Adnane Hassani, Mountassar Maamoun, Rezki Tadrist, Ali Nesba, "A New High Speed and Accurate FPGA.based Maximum Power Point Tracking Method for Photovoltaic Systems", International Journal of Power Electronics and Drive Systems, Vol. 8, no. 3, pp. 1335-1344, September 2017.

[28] Jia Cunliang, Wang Yanxiong, Wang Zerong, "Photovoltaic Array Maximum Power Point Tracking Based on Improved Metod", TELKOMNIKA, Vol. 14, no. 2, pp. 404-410, June 2016.

[29] M. Satyanarayana, P. Satish Kumar, "Analysis and Design of Solar Photovoltaic Grid Connected Inverter", Indonesian Journal of Electrical Engineering and Informatics, Vol. 3, no. 4, pp. 199-208, December 2015.

[30] N. W. A. Lidula and A. D. Rajapakse, "Microgrids research: A review of experimental microgrids and test systems," Renew. Sustain. Energy Rev., vol. 15, no. 1, pp. 186-202, 2011. 